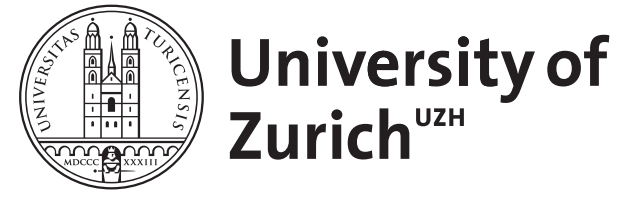

Zurich Open Repository and Archive

University of Zurich

University Library

Strickhofstrasse 39

CH-8057 Zurich

www.zora.uzh.ch

Year: 2002

\title{
Does ontology exist?
}

Glock, Hans Johann

DOI: https://doi.org/10.1017/S0031819102000268

Posted at the Zurich Open Repository and Archive, University of Zurich

ZORA URL: https://doi.org/10.5167/uzh-56244

Journal Article

Published Version

Originally published at:

Glock, Hans Johann (2002). Does ontology exist? Philosophy, 77(2):235-256.

DOI: https://doi.org/10.1017/S0031819102000268 


\title{
Does Ontology Exist?
}

\author{
HANS-JOHANN GLOCK
}

\begin{abstract}
Dances, romances, things of the night, sunshine and holidays, postcards to write, budding trees, autumn leaves, a snowflake or two, all kinds of everything remind me of you!

('All Kinds of Everything' by D. Lindsay and J. Smith)
\end{abstract}

The logical positivists denounced ontology as a branch of metaphysics that is either trivial or meaningless. Proper philosophy does not make claims about reality. Instead of trying to compete with science, it turns into the 'logic of science', a second-order investigation into the conceptual framework of the special disciplines. And when Heidegger held forth about 'Being' and 'Nothing', Carnap had no problem in showing that it involved a linguistic blunder, a case of mistaking quantifiers for names of peculiar objects. But from the fifties onward, attitudes changed. Instead of having a good laugh about Heidegger's 'The Nothing noths', analytic philosophers took up ontology themselves, and with a vengeance. The war cry that philosophy should concern itself with things instead of words, with reality instead of concepts, has gained wide currency. Most analytic philosophers would repudiate the idea that ontology investigates 'Being' or 'Nothing' as based on reification. Nevertheless, it is generally assumed that ontology deals with two problems, which are more fundamental than those of epistemology, semantics or even $\operatorname{logic}:^{1}$

What kinds of things exist?

What is the nature or essence of these kinds?

My paper challenges this 'ontological turn'. It attempts to rehabilitate the deflationary approach to ontology championed by

${ }^{1}$ See S. Laurence and C. Macdonald (eds), Contemporary Readings in the Foundations of Metaphysics (Oxford: Blackwell 1998), 3-4; D. Armstrong, 'The Causal Theory of the Mind', Mind and Cognition: A Reader, W. G. Lycan (ed.) (Oxford: Blackwell, 1990), 37-9.

(C)2002 The Royal Institute of Philosophy

Philosophy 772002 


\section{Hans-Johann Glock}

Wittgenstein, Carnap and Ryle. ${ }^{2}$ There are reasons for thinking that ontology does not exist, not, that is, if it is conceived as a distinctively philosophical investigation into the components of reality. Of course there are ontologists, people who attend conferences on the mereology of artefacts or write articles about the causal role of tropes. But their endeavours are best understood as contributions to a certain kind of conceptual analysis. Instead of establishing whether, for example, tropes really exist, they in effect elucidate the concept of a property and its relation to the concept of a bearer of a property, or the role that property concepts play in causal explanations.

Analytic ontologists tend to deny the existence of even the most mundane and familiar things. Eliminative materialists, for example, deny that there are minds. In a similar vein, Quine, who prides himself on a robust sense of reality, is nevertheless driven to the contention that the only things that strictly speaking exist are pure sets, that is, sets which do not even contain any individuals (TT 17-8). ${ }^{3}$ Such extraordinary claims lend at least prima facie support to the idea that philosophy cannot contribute directly to the investigation of reality by other disciplines. Philosophers are good at arguing,

2 Such an approach has recently been defended by S. Yablo, 'Does Ontology Rest on a Mistake?', Proceedings of the Aristotelian Society Supplementary LXXII (1998). But unlike Yablo, I do not take my cue exclusively from Carnap. And although I defend a version of the external/internal distinction, this defence differs from his. He contends that internal claims like 'There is a city of Chicago' are part of a make believe game. This contention is at odds with Carnap, because it treats internal rather than external statements as non-factual. It is also implausible, because, as Yablo himself writes (259), statements do not come any more literal than that. In any event, the external/internal distinction is less important to my deflationary case than considerations about quantification, the concepts of existence and of an object, and the nature of logical paraphrase.

3 References to works by Quine will be abbreviated as follows: MLMathematical Logic (New York: Harper, 1952; 1. edn. 1940); FLPVFrom a Logical Point of View (Cambridge, Mass.: Harvard University Press, 1980; 1. edn. 1953); WO-Word and Object (Cambridge, Mass.: MIT Press, 1960); WP-Ways of Paradox and Other Essays (Cambridge, Mass.: Harvard University Press, 1976; 1. edn. 1966); OR-Ontological Relativity and Other Essays (New York: Columbia University Press, 1969); PL-Philosophy of Logic (Englewood Cliffs, N.J.: Prentice-Hall, 1970); TT-Theories and Things (Cambridge, Mass.: Harvard University Press, 1981); PT-Pursuit of Truth (Cambridge, Mass.: Harvard University Press, 1992; 1. edn. 1990). 
analysing, interpreting and preaching; but about reality they tend to know even less than ordinary mortals.

In my view, philosophy should be a second-order discipline, one that investigates not reality itself, but the conceptual framework that common sense and science employ in describing reality. Its proper 'ontological' task consists not in establishing what there is, or in arguing for or against the existence of entities, but in clarifying what non-philosophical claims concerning the existence of various things amount to, and in analysing concepts like those of existence, of an object or of reality. I do not purport to provide conclusive arguments for this position, but I hope to challenge the strident selfimage of contemporary ontology. The currently popular conceptions of the subject, at any rate, do not license the idea that ontology provides us with genuinely philosophical insights into reality.

I start out by distinguishing four main sources of the renaissance of ontology-Strawson's descriptive metaphysics, Kripke's realist semantics, the Australian 'truth-maker principle' and Quine's naturalistic conception of ontology. I shall indicate briefly why, in my view, the first three do not rehabilitate ontology (section 1). In the remainder I shall concentrate on Quine, who has been the most influential and methodologically most scrupulous inspiration behind analytic ontology. According to Quine's position (sketched in section 2), ontology helps science in drawing up an inventory of the world. Through logical paraphrase it identifies and reduces the ontological commitments of our best scientific theories. Against this programme, I shall argue that Quine's conception of ontological commitment is inadequate, and that his logical paraphrase cannot contribute to the exploration of reality, but at most to the clarification of our conceptual scheme.

Section 3 maintains, against Quine's criterion of ontological commitment, that we do not treat everything that we refer to or quantify over as existent. This verdict encourages deflationary approaches to ontology, according to which talking about abstract objects need not involve the Platonist picture of entities beyond space and time. In section 4, I shall defend Ryle's 'existential' and Wittgenstein's 'objectual' deflationism. Section 5 lends qualified support to Carnap's 'linguistic' deflationism. It also argues that, unlike scientific theory building, logical paraphrase does not alter our existential assumptions, but only our way of expressing them. Consequently, the crafting of such paraphrases does not contribute to the scientific exploration of the world. I close with some brief remarks on the relation between science, conceptual analysis and other potential rehabilitations of ontology (section 6). 


\section{Hans-Johann Glock}

\section{The Analytic Renaissance of Ontology}

There are four main ideas that have contributed to the rise of analytic ontology. In rough chronological order, these are: Quine's naturalistic conception of ontology, Strawson's revival of what he calls 'descriptive metaphysics', the essentialist metaphysics derived from Kripke's and Putnam's realist semantics, and the AustroAustralian 'truth-maker principle'.

In this section I shall discuss the last three. Of course, I cannot do them full justice in such a short space. But I want to do indicate how one might resist the conclusion that they furnish philosophical insights into the constitution and essence of reality. My qualms are ultimately fuelled by a Kantian worry about ontology. ${ }^{4}$ Kant maintained that there could be no a priori truths about reality, because experience is our only way of finding out about reality. Even if there are synthetic a priori truths, these are not de re. Instead of describing mind-independent essences of objects, they articulate 'necessary preconditions for the experience of objects', that is, the essential features of the way we experience them. The ontological search for essences is thus transformed into a second-order reflection on our conceptual scheme.

Strawson's descriptive metaphysics respects this stricture, and is metaphysics only in a Kantian sense. It investigates not de re essences, but the conceptual framework of our thought and experience. Strawson's aim is 'to describe the actual structure of our thought about the world', 'the most general features of our conceptual structure'. To be sure, he talks about relations of 'ontological priority' between different types of objects. In fact, however, what he has in mind are connections and dependencies between various parts of our conceptual framework. A type of thing $\mathrm{X}$ is ontologically prior to a type of thing $\mathrm{Y}$ not because it underlies or explains the latter's existence. Rather, objects of type $\mathrm{X}$ are ontologically prior to objects of type $\mathrm{Y}$ if and only if the identification and re-identification of objects of type $\mathrm{X}$ is presupposed by the identification and re-identification of objects of type Y, but not vice versa. ${ }^{5}$

The ontological revival inspired by Kripke and Putnam also pays homage to Kant. It grants that we cannot establish the real essences of things through a priori Wesensschau, while insisting that we can

${ }^{4}$ Critique of Pure Reason A 247/B 303.

${ }^{5}$ Strawson, Individuals (London: Methuen, 1959), 9, 17, 59; see also A. Quinton, The Nature of Things (London: Routledge \& Kegan Paul, 1973), $246-7$. 
do so with the help of science. According to realist semantics, theoretical identifications like

\section{(1) Water is $\mathrm{H}_{2} \mathrm{O}$}

are both a posteriori, because they are discovered by science, and necessary, because they involve rigid designators that pick out the same things in all possible worlds, a substance with a particular microstructure in the case of 'water'. ${ }^{6}$

The claim that (1) is necessary a posteriori can be contested. ${ }^{7}$ But the best deflationary response is to question the step from realist semantics to essentialist metaphysics. Even if (1) is necessary a posteriori, this does not automatically show that ontology provides us with insights into the essences of things. As realist semantics acknowledges, (1) is a discovery of science, not of ontology. The discovery essentialist metaphysicians might claim to be their own is rather

\section{(2) $\square$ (Water is $\mathrm{H}_{2} \mathrm{O}$ )}

But where does the modal surplus value of (2) derive from? Not, it is plausible to argue, from intrinsic modal properties of water. Instead, its grounds lie in our linguistic practice, namely in the fact that we use 'water' as a rigid designator. The necessary a posteriori status of (1) can be seen as the result of combining an empirical discovery about the world, namely that $\mathrm{H}_{2} \mathrm{O}$ is the chemical composition of the stuff we call 'water', with a non-empirical linguistic convention, namely that, in any possible situation, nothing will count as water unless it has the composition of that stuff (whatever it may turn out to be). ${ }^{8}$ This explains why Kripke and Putnam back their accounts of statements like (1) not by scrutinizing reality, but by appeals to our linguistic intuitions or to 'what we would say' in certain counterfactual situations. It supports the division of labour between science and philosophy. The former tells us what reality is like, on the basis of experience, the latter tells us what reality must be like, given our conceptual framework.

The truth-maker principle is intimately linked to correspondence

${ }^{6}$ S. Kripke, Naming and Necessity (Oxford: Blackwell, 1980); H. Putnam, Mind, Language and Reality (Cambridge: Cambridge University Press, 1975), ch. 12.

${ }^{7}$ E.g. A. Stroll 'What Water Is or Back to Thales', Midwest Studies in Philosophy XIV (1989); J. Dupré, The Disorder of Things (Cambridge, Mass.: Harvard University Press, 1993), 25-6.

${ }^{8}$ See A. Sidelle, Necessity, Essence, and Individuation: A Defence of Conventionalism (Ithaca: Cornell University Press, 1989). 


\section{Hans-Johann Glock}

theories of truth, and it has a long history from Aristotle to Dummett. Its most vocal contemporary proponents are admirers of the Austrian philosophical tradition on the one hand, Australian metaphysicians on the other. ${ }^{9}$ In its most general form, the principle maintains that every true proposition owes its truth to something, or is made true by something. The ontological import is supposed to be that we can gain insights into reality by investigating what sort of things are the truth-makers of what types of truths.

One idea behind the truth-maker principle is that every truth corresponds to something in reality that makes it true, notably a fact or state of affairs. Thus

(3) Snow is white

is made true by the fact that snow is white. However, the sense in which the fact that $p$ makes true the sentence ' $p$ ' is logical rather than causal. It is like 'telling lies makes one a liar' rather than 'drinking alcohol makes one dizzy'; it does not refer to a causal relation between two independent events or conditions. ${ }^{10}$

The question 'What makes it true that snow is white?' or 'Why is it true that snow is white?' can be understood in two different ways. One is to regard them as equivalent to 'What makes snow white?' or 'Why is snow white?'. Answers to these questions certainly refer to reality, namely to snow and its physical properties. These answers, however, are given by science rather than philosophy. Moreover, what makes a statement that $p$ true in this sense is never (the fact) that $p$, but rather (the fact) that $q$, etc. On the other hand, the question can be understood as asking what fact verifies (3). This question can be answered by philosophy. If it is true that $p$, then what verifies the proposition that $p$ is the fact that $p$. Yet this answer tells us nothing about reality, but only about the logical equivalence between 'It is true that $p$ ' and 'It is a fact that $p$ '. ${ }^{11}$

See, respectively, K. Mulligan, P. Simons and B. Smith 'TruthMakers', Philosophy and Phenomenological Research 44 (1984) and D. Armstrong, A World of States of Affairs (Cambridge: Cambridge University Press, 1997), esp. 150.

${ }^{10}$ B. Rundle, Grammar in Philosophy (Oxford: Oxford University Press, 1979), $\S \S 42-3$.

${ }^{11}$ Mulligan, Simons and Smith disdain facts and instead opt for a mixed bag of truth-makers, including events, states, natural kinds, etc.. This approach is incapable of accounting for all truths, even of an empirical kind; see W. Künne, Conceptions of Truth (Oxford: Oxford University Press, 2002), ch. 3.5.2. But this drawback may be outweighed by an advantage, namely that the connection between truth and truth-maker is no longer the trivial logical equivalence between ' $p$ ' and 'it is a fact that $p$ '. For 240 
If these reflections are along the right lines, among the current contenders, only Quine remains in the running. His work was the first and most influential force behind the rise of analytic ontology. Furthermore, in two respects it is the most auspicious. Analytic ontologists tend to disparage epistemological and methodological questions as derivative. As a result, they are often oblivious to the challenge of explaining how philosophy can gain insight into reality and essences. By contrast, Quine assigns pride of place to the question of how we acquire our knowledge about the world, and he has made sophisticated contributions to the methodological questions of what ontology is and how it should proceed.

Quine also avoids the Kantian objection ab initio, since he ridicules the idea that philosophers are capable of getting essences into the hair-crosses of their intellectual periscopes, whether by a priori or by empirical means. He also denies that a priori philosophical reflection can establish what kinds of things there are. In short, Quine is 'no champion of traditional metaphysics'. Nevertheless, he finds a use for 'the crusty old word' 'ontology', which he regards as nuclear to its traditional employment (WP 203-4). Like traditional ontology, Quine's naturalistic ontology seeks to establish what kinds of things there are. But it does not pursue this aspiration directly or in isolation. Instead, it attempts to help science in drawing up an inventory of the world.

\section{Ontological Commitment and Ontological Parsimony}

The beginning of Quine's article 'On what there is' is both abrupt and brilliant:

example, the truth-maker of 'Lincoln was assassinated' is the event of Lincoln's assassination and of 'Madonna is famous' the state of Madonna being famous. This might seem to open up the prospect of ontological discoveries concerning some types of truth at least. However, though less trivial, the connection between these truths and their truth-makers remains a priori and conceptual: 'The event of Lincoln's assassination occurred', for example, is logically equivalent (though stylistically inferior) to 'Lincoln was assassinated'. It must be granted that Mulligan, Simons and Smith also provide an ingenious example in which a truth-maker is empirically discovered: if 'Alec has viral hepatitis' is a truth, we can find out whether the truth-maker is Alec's state of having hepatitis A, or of having hepatitis B, or both. But once more there is a clear line between, on the one hand, the a posteriori task of discovering either what types of viral liver infections there are (they have added to this list in the meantime) or what type Alec suffers from, and, on the other, the a priori task of noting that, given a certain understanding of hepatitis, any one of these states is sufficient for the statement being true. 


\section{Hans-Johann Glock}

A curious thing about the ontological problem is its simplicity. It can be put in three Anglo-Saxon monosyllables: 'What is there?' It can be answered, moreover, in a word-'Everything'-and everyone will accept the answer as true (FLPV 1).

Quine's answer to the ontological problem presupposes that everything, that is, every thing exists. This places him in the Aristotelian tradition, which treats the terms 'existent', 'being', 'thing', and 'object' as equivalent (OR 100-1). There is another tradition, which treats 'existence' as narrower than 'being' and 'thing', notably as confined to concrete things. Thus Meinong maintained that abstract objects 'subsist' without existing.

Quine follows tradition in yet another respect. Ontology is not concerned with the existence of particular things or of things in particular spaces or at particular times, but with the question 'What kinds of objects are there?' (FLPV 1). Indeed, its primary concern is with the existence of highly general categories of things, such as material objects, mental phenomena or abstract entities.

Quine's conception of ontology rests on five main points:

- the naturalistic assimilation of philosophical and scientific questions of existence;

- the instrumentalist and pragmatist view that establishing the existence of objects of a certain kind is a matter of establishing that such objects should be 'posited' for the sake of explaining experience;

- the attempt to find a criterion of 'ontological commitment', a way of determining what types of entities a given theory assumes to exist;

- the method of formal paraphrase: the ontological commitments of a theory are established and, where possible, reduced by translating it into a formal language ('canonical notation').

- a programme of ontological parsimony that combines a qualified nominalism with an unqualified extensionalism.

In line with his naturalistic conception of philosophy as part of science, Quine denies that there is a fundamental difference between the existence questions debated in the special sciences-e.g. 'Are there prime numbers greater than 100?', 'Are there quarks?', and the existence questions posed by philosophers such as 'Are there numbers?' or 'Are there material objects?'. The difference between the scientific and the philosophical problems is one of degree, not of kind. The philosophical questions are special only in being concerned with the most general and fundamental 'furniture of our universe' (WO 254, see 271-2; WP 211). 
Our ontological views are an integral part of our 'overall conceptual scheme', our most comprehensive world-view, which includes scientific and common sense beliefs. They serve the purpose of providing the simplest structure which fits the 'disordered fragments of raw experience'. Hence they are subject to the same pragmatic considerations (explanatory power, simplicity, etc.) as scientific theory building in general. Such considerations speak strongly in favour of physical objects. Nevertheless, even they are merely 'posits'. They are not simply given as part of reality, but postulated for the sake of simplifying our account of the 'flux of experience' (FLPV 16-7, 44-5, 105-6).

Quine's third point is the idea of ontological commitment. Our statements and beliefs commit us to the existence of certain entities. For example, by accepting

(4) There is a prime number greater than 100

we also accept that numbers exist, since this statement implies

(5) There are numbers.

Quine's initial question is not 'What sorts of objects do in fact exist?', but rather 'What sorts of objects do given theories or beliefs take to exist?'. He is concerned with 'ascribing' rather than 'evaluating' ontologies (FLPV viii). However, in Quine's naturalism, the two questions are intimately linked. Science is our best guide to what exists. By establishing what things our best current scientific theory takes to exist, we also provide the best theory of what things actually exist. Still, as we shall see, Quine's ontology does not simply follow current science; it is also driven by distinctly philosophical standards of ontological admissibility.

In order to avoid commitment to objects of an unwelcome kind we must establish what the ontological commitments of our theories are. This requires a criterion for determining what entities a theory is obliged to accept as existing. The general idea of ontological commitment is straightforward: a theory is committed to those objects which must exist if it is true (OR 93). A theory $T$ assumes the existence of entities of type $K$ iff $T$ entails or presupposes that there are entities of type $K$. The point of Quine's criterion of ontological commitment is to pinpoint which types of expressions occurring in $T$ commit us in this way.

This brings in the fourth pillar of Quine's approach. He deals with this question by translating our beliefs and theories into a formal language. This 'regimentation' serves two closely connected purposes. First we reveal the ontological commitments of our 


\section{Hans-Johann Glock}

present theories by translating them into a formal language. Then we reduce these commitments by reforming that language. The ultimate goal is to provide a 'canonical notation', that is, a logical notation that displays and minimizes our ontological commitments, while being adequate for expressing all our scientific theories. Though 'austere', canonical notation should be capable of displaying 'all traits of reality worthy of that name' (WO 228).

In his quest for a canonical notation, Quine starts out with the first-order predicate calculus, which contains the logical constants, individual variables, singular terms and general terms (predicates). Prima facie, the carriers of ontological commitment are singular terms, since they purport to refer to or denote objects. But assessing ontological commitments simply on the basis of singular terms is problematic: the statement 'Pegasus does not exist' does not commit one to the existence of Pegasus. Quine avoids this problem by eliminating singular terms along the lines of Russell's theory of descriptions (FLPV 5-8). The resulting notation contains only propositional connectives, predicates, the identity sign, quantifiers and their variables. It reveals ontological commitments by showing what existential statements a given theory implies. Quine concludes that ontological responsibility attaches exclusively to the bound variables of quantification. For example, in order for ' $\exists x(F x \& G x)$ ' to be true, the domain over which the bound variable ' $x$ ' ranges must contain at least one object that is both $F$ and $G$.

Quine's criterion of ontological commitment is based on the objectual interpretation of quantification. For him, ' $(x) F x$ ' claims not that all substitution instances of ' $F x$ ' are true, but that ' $F x$ ' is true of all members of a domain of objects. Substitutional quantification is irrelevant to ontology. What counts are the values of the variables, the objects in the domain over which the variables range, not the substituends of these variables, that is, the expressions that can be substituted for them (PL 91-4). Accordingly, a theory $T$ is ontologically committed to entities of type $K$ iff some entities of type $K$ must be counted among the values of the variables in order for $T$ to be true. 'To be is to be the value of a bound variable' (FLPV 14-5). We assume the existence of objects of a given sort by quantifying over them, that is, by employing variables of quantification that must be presumed to include such objects among their values.

However, our commonly accepted beliefs and theories refer to or quantify over a wide range of things, such as particulars, times and places, properties, relations, quantities, propositions, numbers, facts, species, actions, beliefs, possibilities, institutions, etc. Quine's 
ambition is to clear out this ontological 'slum', which he regards as a 'breeding ground for disorderly elements' (FLPV 4). Therefore, the paraphrase of our beliefs in canonical notation is not indiscriminate. Rather, it is guided on the one hand by a general aim of 'ontological parsimony' and 'economy' (WO 270; PL 69), and, on the other, by standards of ontological admissibility like clarity and scientific respectability. The question is: 'how economical an ontology can we achieve and still have a language adequate to all purposes of science?' (WP 201).

Quine's programme of ontological parsimony proceeds by 'explication'. It does not aim at synonymy, but eliminates expressions in favour of alternatives which serve the same cognitive purposes while avoiding unwanted ontological commitments. We get rid of attributes, for example, by paraphrasing

(6) Red is a colour

as

$\left(6^{\prime}\right)$ For all $x$, if $\mathrm{x}$ is red then $x$ is coloured

which avoids commitment to the existence of attributes. In the same vein, numbers and ordered pairs are reduced to classes (WO $\$ § 53-4)$. Quine is a conditional nominalist, yet an unconditional extensionalist (see OR 21-3; TT 182-4). He tries to avoid abstract objects as far as possible, but concedes that mathematics cannot do without classes. By contrast, his repudiation of intensional abstract entities like meanings, properties and propositions is absolute, because he thinks that they lack criteria of identity.

\section{Ontology and Quantification}

Quine maintains that his criterion of ontological commitment is a truism (TT 175; P'T 25-7). We take to exist what we say that there is, or what must exist if what we say is to be true. But Quine's criterion captures what we take to exist only if his objectual ' $\exists x$ ' encapsulates the commitments of our 'there is' and its cognates. Indeed, the criterion is specifically designed to ensure that only the variables that replace singular terms carry ontological responsibilities. Abstract singular terms like 'redness' but not concrete general terms like 'red' commit us to attributes. This is directed against two kinds of 'offenders' (WO 240-1).

On the one side, there are what I shall call ontological inflationists, who hold that even concrete predicates like 'is red' refer to attributes 


\section{Hans-Johann Glock}

and thereby commit us to intensions. On the other side, there are ontological deflationists, who hold that even employing abstract singular terms like 'redness' or quantifying over numbers does not commit us to dubious abstract objects.

Prima facie, at least, the inflationist offenders are right by Quine's own lights. For general terms in predicative position are also accessible to quantifiers and hence seem to commit their users to the existence of attributes. ${ }^{12}$

(7) Betty is witty and Sarah is witty $F \mathrm{a} \& F \mathrm{~b}$ entails not just

(8) Someone is witty $\exists x \mathrm{~F} x$

but equally

(9) There is something Betty and Sarah both are (viz. witty)

$\exists \Phi(\Phi \mathrm{a} \& \Phi \mathrm{b})$

At this point, Quine's objectual interpretation of quantification is crucial to his position. He alleges that locutions like (9) are 'meaningless' and do 'violence to grammar' (ML \$34). This allegation is based on the conviction that all genuine existence statements amount to 'There is an object $x$ such that' and can hence be captured by objectual quantification.

Such is simply the intended sense of the quantifiers ' $(x)$ ' and ' $\exists x$ ': 'every object $x$ is such that', 'there is an object such that'. The quantifiers are encapsulations of these specially selected, unequivocally referential idioms of ordinary language (WO $\$ 49$; see FLPV 102-6; OR 97, 106; PL 89; TT 174-5).

On this assumption, (9) is indeed infelicitous. It would have to be rendered as

$\left(9^{\prime}\right)$ There is an object $\Phi$ such that a is $\Phi$ and b is $\Phi$

Yet (9) does not claim that there is an object-the property of being witty-Betty and Sarah both are, but that there is something they both are, namely witty.

But why should quantification have to be understood objectually? Quine's answer is that: 'Variables are pronouns, and make sense only in positions which are available to names' (WP 198). However, pronouns can occur in other positions. To be more precise, ordinary

${ }_{12}$ P. F. Strawson, Logico-Linguistic Papers (London: Methuen, 1971), 65-6; M. A. E. Dummett, Frege: Philosophy of Language (London: Duckworth; 1. edn. 1973), 59-61. 
language features not just pro-nouns, as in 'Betty is witty but she is gentle', but also pro-adjectives ('Not just the Kremlin is red, the Tower is so too') and pro-verbs ('Sarah goes on vacation, and so does Peter'). Pace Quine, therefore, there are perfectly acceptable 'idioms of ordinary language' (ML \$16) which capture quantification into predicate position. ${ }^{13}$ 'There is something which ...' has a wider scope than 'there is an object which ...', the idiom on which Quine focuses. 'Something' is syntactically transcategorial: it can quantify into the positions of both singular term, as in (8), and of predicates, as in (9).

The question arises of how the predicative quantification of (9) should be understood. The standard move is to conceive of it in terms of substitutional quantification. ${ }^{14}$ But substitutional quantification cannot deal with objects no one has ever labelled or attributes no one has ever ascribed (OR 63-7, 106). Fortunately, this difficulty can be avoided by a third option, an understanding of ' $\exists \Phi$ ' which is neither objectual nor substitutional but what Prior called 'nonnominal'. ${ }^{15}$ It amounts to a non-substitutional understanding of quantification into predicate position. The quantifiers bind not name variables but predicate variables. That is to say, the substitution class of the variables is not the class of singular terms but the class of predicates. By contrast to substitutional quantification, the variables have not just substituends but also values, a range of objects with which they are associated, namely properties. By contrast to objectual quantification, the substituends of predicate variables do not name these values (attributes), they ascribe them.

It emerges, therefore, that Quine cannot convict the inflationist offenders simply by ruling statements like (9) out of court. One can make existential claims without using the objectual quantifier, and his criterion of ontological commitment is too narrow. According to Quine, all values are objects (WP 182). But in that case, to be is not simply to be the value of a variable. There is something Betty and Sarah both are. But what they both are is not an object, like the property of being witty. What they both are is witty. While 'wit' and 'being witty' are names of a property, 'witty' is not.

Quine's position faces an even more serious predicament.

${ }^{13}$ See W. Künne, Abstrakte Gegenstände (Frankfurt: Suhrkamp, 1983), ch. 3.3.

${ }^{14}$ S. Haack (1978), Philosophy of Logics (Cambridge: Cambridge University Press), 50-6.

${ }^{15}$ Objects of Thought (Oxford: Clarendon Press, 1971), ch. 3, 68; see P. Hugly and C. Sayward, Intensionality and Truth (Dordrecht: Kluwer, 1996), 174-208; Künne, Conceptions of Truth, ch. 6.2.3. 


\section{Hans-Johann Glock}

Objectual quantification has turned out not to be a necessary condition for existential claims and assumptions. But it is not sufficient either. Quine's criterion of ontological commitment turns accessibility to quantification into the hallmark of existential assumptions. Even if one sticks to the untenable restriction to singular terms, however, replaceability by 'something' transpires to be a trivial operation. It does not entail that the replaced phrases even purport to refer to something that exists. If Pegasus does not exist, then something doesn't exist. ${ }^{16}$ And if the round square is a Meinongian nightmare, then something is a Meinongian nightmare. We can talk about and quantify over all kinds of everything, including things that do not or cannot exist. It is therefore problematic to impute serious ontological responsibilities to phrases merely because they can be replaced by 'something'.

Quine could insist, however, that such responsibility must attach to 'there is something...' and its cognates. It may indeed sound awkward to say that there are things that do not exist. But there is a use of vernacular quantifiers that does not necessarily imply existence. ${ }^{17}$ There are, for example, fictional characters with a stammer, and there is nothing awkward in denying that fictional characters exist. And even if one were to insist that fictional characters exist, one could not maintain that they are real. If any condition attaches to quantification, it would seem to be countability or at least identifiability rather than existence or reality. We can quantify over those things we can identify and count, which includes fictional characters among other things. By the same token, Quine's famous answer to the ontological question is wrong. Not everything exists. We refer to and quantify over things that do not. And Quine is even further off target when he invokes "the ordinary usage of "real"' in support of his contention 'Everything, of course, is real' (WP 225). Since some things are not real, it cannot be the case that everything is real.

These conclusions in turn lend credence to the deflationist

${ }^{16}$ Rundle, op. cit., 199-200.

${ }^{17}$ This recognition may lie behind W. Sellars' unsubstantiated 'working hypothesis' that not all uses of the (objectual) existential quantifier express an existential claim (Science and Reality (London: Routledge, 1963), 116). A formal distinction between committal and non-committal quantifiers is to be found in 'T. Hofweber, 'Quantification and Non-Existent Objects', Empty Names, Fiction and the Puzzles of Non-Existence, A. Everett and 'T. Hofweber (eds), (Stanford: CSLI Publications, 2000). My version of the distinction is connected to two other deflationary ideas, discussed in the next section, namely Ryle's claim that 'exists' is ambiguous and the distinction between a logical and a weighty concept of an object. 
offenders, whom Quine charges with underestimating their ontological commitments. Though reference to and quantification over things is much more pervasive then he allows, it may also be less harmful. To be sure, there is a difference between fictional and abstract entities, in that reference to and quantification over the latter does involve existential assumptions of some kind. But the question remains whether it commits us to a dubious Platonist metaphysics.

\section{Ontological Evasions}

Platonism holds that abstract objects like numbers, properties and propositions inhabit a super-natural world beyond space, time and causation, a world to which we-or at any rate suitably trained logicians and mathematicians - have access by a kind of intellectual intuition'. Nominalists protest that this hinterworld is a myth, and that the signs which apparently refer to its denizens are flatus vocis that can be avoided in respectable discourse.

Ontological deflationists try to undermine this debate. For them, the way to avoid Platonism does not lie in purging our theories of reference to and quantification over abstract objects. Like Quine, they view the prospects of this enterprise as dim. Unlike Quine, they regard the attempt to avoid intensional abstract terms as equally futile. At the same time, the deflationists do not accept that such failure would lumber us with mysterious entities. Once we clarify what it is for abstract singular terms to refer, they claim, we shall realize either that they do not refer to genuine objects or existents at all, or that the existence of abstract objects is at any rate a perfectly intelligible and low-key affair.

How convincing are these pleas of ontological innocence? I shall discuss this question by considering three different versions of deflationism, which I shall call existential, objectual and linguistic. ${ }^{18}$

Existential deflationism is based on Ryle's claim that the term 'exists' is ambiguous. ${ }^{19}$ In the sturdy spatio-temporal sense in which material objects exist, abstract objects do not, but they were never meant to by our pre-theoretical statements about numbers, properties or propositions. The dispute between Platonism and nominalism would then be based on a failure to keep apart these different

${ }^{18}$ A position that I shall ignore here is contextual deflationism, the view that abstract singular terms are harmless because of Frege's context-principle. See Dummett, op. cit., ch. 14, and, for a critical discussion, B. Hale, Abstract Objects (Oxford: Blackwell, 1987), ch. 7.

${ }^{19}$ The Concept of Mind (Harmondsworth: Penguin, 1980; 1. edn. 1949), $23-4$. 


\section{Hans-Johann Glock}

notions of existence. Quine concedes that 'in a derivative way', there are 'two senses of existence', a 'common sense' and a 'philosophical sense'. In the former, a nominalist can accept 'There are prime numbers' as a façon de parler. But the philosophical sense in which the nominalist must deny that there are numbers 'is rather to be respected as literal and basic than deplored as a philosophical disorder'. In that literal ontological sense, someone adverse to Platonism must either 'paraphrase or retract' (OR 98-100).

According to Quine, the idea that 'exists' is ambiguous in a philosophically relevant sense falls foul of the proper criterion for ambiguous terms. A term is ambiguous only if in one and the same context it can make for both a true and a false statement. ${ }^{20}$ Ryle might respond that 'Abstract objects exist' turns out true if it means 'exist period' and false if it means 'exist in space and time'. Perhaps this comeback is question begging, since it simply assumes that 'exists' has these two distinct senses rather than demonstrating it. With respect to fictional entities, however, our previous discussion provides an independent argument. 'Quasimodo exists' is true or false depending on whether or not 'exists' is understood as presuming reality.

Furthermore, Quine's criterion of ambiguity can be contested. If change of truth-value must be possible in all contexts, then it excludes paradigms of lexical ambiguity: in 'I had a drink of port' the understanding 'naval harbour' makes for nonsense rather than truth or falsehood. If change of truth-value must be possible only in some context, then univocal terms come out as ambiguous: a single utterance of 'This is awful' can express something true and express something false depending on one's standards, but 'awful' is not ambiguous.

Finally, the argument can be turned against Quine. If ambiguity is captured by his criterion, this only goes to show that it is a rare phenomenon which does not exhaust the possibility of equivocations. The criterion entails, for example, that the differences between 'Socrates is snub-nosed' and 'Socrates is the husband of Xanthippe' cannot derive from an ambiguity of 'is'. For in the context of 'Socrates ... snub-nosed', glossing 'is' as 'is identical with' does not turn a true statement into a false one, but into ungrammatical gibberish. Nevertheless, Quine would be the first to acknowledge that there is a fundamental difference between the 'is' of predication and the 'is' of identity. Similarly, even if the word 'exists' is univocal, statements claiming the existence of concrete and

${ }^{20}$ WO 241-2, §27; FLPV 3, 131; Rundle, op. cit., §3. 
abstract objects respectively may yet have a fundamentally different role. This would explain why a sentence like 'There are dogs, prime numbers and properties' has an air of syllepsis; it is reminiscent of 'The bench, the liquor and the exam were hard'.

Objectual deflationism derives from Wittgenstein. It maintains that so-called abstract objects are not really bona fide objects at all. They lack many of the characteristic features of ordinary objects, for example the capacity to be visualized or pointed at. ${ }^{21}$ This claim invokes the common sense notion of a distinct, relatively enduring and sufficiently large material object. However, there is also a wider logical conception associated with Frege. An object is simply anything one can refer to (and hence characterize by a predicate); $a$ is an object if and only if ' $a$ ' is a singular term. Quine shares that conception, except that for him the ultimate vehicles of reference are variables rather than singular terms. An object is anything that is the value of a variable of quantification.

Wittgenstein complained that according to the logical conception even the coincidence of an eclipse of the moon and a court case is an object. Künne has replied that there is a perfectly intelligible and non-philosophical sense in which one can regard this coincidence as an object. One can refer to it and claim of it, for example, that it was an object of heated debates. ${ }^{22}$ But this only goes to show that even the vernacular operates with two distinct notions of an objectobject of reference or discourse on the one hand, material object on the other. It does not show that there is no difference between the two. Although holes and gaps are objects of reference, 'The hole in the object grew larger' and 'There is a gap between the two objects' do definitely not imply 'The object in the object grew larger' or 'There is an object between the two objects'.

Objectual deflationism now comes to this. One must grant that numbers, attributes, propositions, etc., are objects of reference. But this is only to grant that we can identify and talk about them. Just as the concrete singular term 'Betty' occupies a referring position with respect to 'is witty' in 'Betty is witty', we can move to secondlevel predication in which a corresponding abstract singular term can occupy referential position relative to a higher-level predicate:

(10) Wit is desirable in a friend

${ }^{21}$ Remarks on the Foundations of Mathematics (Oxford: Blackwell, 1978; 1. edn. 1956), 262-3. See Dummett, op. cit., 70-80; I. Dilman, Quine on Ontology, Necessity and Experience (London: Macmillan, 1984), 71.

${ }^{22}$ Abstrakte Gegenstände, 41; cp. Wittgenstein, Philosophical Remarks (Oxford: Blackwell, 1975), §§93, 115. 


\section{Hans-Johann Glock}

This shows that properties are topics of speech, namely of higherlevel predication. However, this analogy between abstract and concrete objects is 'strictly limited and purely logical'.$^{23}$ Although 'wit' indicates what attribute we are talking about, it does not single out something which we could point at if only we ever managed to visit the Platonic realm.

As long as one really confines oneself to the logical notion of an object, there is nothing mysterious about numbers, attributes and propositions being objects. (10) applies a higher principle of classification ('desirable in a friend') to a property, something associated with a principle of grouping particulars ('witty'), a property which is designated by a nominalization of the first-level predicate. To make sense of that possibility, all we need is the idea that human beings have the ability to engage in second-order discourse, that is, to refer to and to classify ways of classifying ordinary objects. We do not need to postulate a realm of entities that are just like material objects, except that they inhabit a realm beyond space, time and causation. The Platonist view that such a realm is required arises only when the logical notion of an object is illicitly combined with distorted connotations of the every-day notion of a material object. On a minimal logical conception of 'object' that avoids these pitfalls, numbers, attributes and propositions are indeed objects. But that concession is itself minimal. It does not license Quine's fear that reference to or quantification over numbers, attributes and propositions involves the heavy metaphysical prize of postulating a mysterious kind of reality.

\section{Linguistic Frameworks and Logical Paraphrase}

Ontology faces a further challenge, namely by linguistic deflationism. According to this position, associated with Carnap and Wittgenstein, ontological questions may not just be a low-key affair, once freed from metaphysical metaphors, but downright vacuous. To be sure, there are genuine questions of existence. But these are specific; they concern the existence of particular kinds of things and can be solved by the special sciences, including logic and mathematics. By contrast, ontological statements like 'There are

${ }_{23}$ Strawson, Logico-Linguistic Papers, 74; see also Wittgenstein, Philosophical Investigations (Oxford: Blackwell, 1967; 1. edn. 1953), §339; Dummett, op. cit., 229-44, 494-511. 
material objects' or 'Universals do not exist' are at best misleading expressions of allegiance to certain conceptual frameworks or 'forms of language'. ${ }^{24}$

In this vein, Carnap distinguished between two kinds of existence questions. ${ }^{25}$ 'Internal questions' are raised from within a 'linguistic framework' (an interpreted formal language) and involve the existence of particular groups of entities. 'External questions' concern the framework itself and involve the existence of a whole system of entities. Scientific questions like 'Are there neutrinos?' or 'Are there prime numbers greater than $10^{10}$ ?' are of the former kind, while philosophical questions like 'Are there material objects?' or 'Do numbers exist?' belong to the latter. Internal questions are 'theoretical' in nature, that is to say, they allow of true or false answers which are reached by proceeding in accordance with the rules constituting the framework (these rules specify methods of observation in the case of the empirical sciences, methods of computation in the case of the formal sciences). By contrast, external questions are either meaningless or 'practical' in nature. They do not concern the ultimate constituents of reality, as the metaphysical tradition had it, but merely our adoption of a particular linguistic framework. The question of whether numbers exist is either internal to our mathematical framework, in which case the answer is trivially 'yes', or it boils down to the question of whether we should adopt a 'number language', in which case it is to be answered on the basis of pragmatic considerations. But an affirmative answer to that pragmatic question involves no commitment to the existence of numbers, and hence no Platonist metaphysics.

Quine's view that scientific and philosophical existence questions do not differ in kind was developed in explicit opposition to Carnap (WP ch. 19; OR 91-3). His main argument seems to be that the external/internal distinction is so intimately tied to the analytic/synthetic distinction that it collapses with the latter. Recent commentators have rightly repudiated this charge of guilt by association. ${ }^{26}$ Even if Quine's attack on the analytic/synthetic distinction is conclusive, the two distinctions are not identical.

Unfortunately, Carnap for his part has given us no argument for

${ }^{24}$ Dilman, op. cit., chs 1-3; R. L. Arrington, 'Ontological Commitment', Wittgenstein and Quine, R. L. Arrington and H.-J. Glock (eds) (London: Routledge, 1996).

${ }^{25}$ Meaning and Necessity (Chicago: University of Chicago Press, 1956; 1. edn. 1947), Apd. A.

${ }^{26}$ Yablo, op. cit., 235-7; G. Bird, 'Carnap and Quine: Internal and External Questions', Erkenntnis 42 (1995). 


\section{Hans-Johann Glock}

accepting that philosophical questions of existence differ sharply from scientific ones in concerning the adoption of a way of speaking. ${ }^{27}$ But perhaps this lacuna can be filled by exploiting a widely noted feature of ontological questions and statements. Unlike ordinary existence claims and questions, they often strike even philosophers as peculiar or ridiculous. Can there really be a serious question as to whether numbers, properties, languages or computer programmes exist? A remark by Wittgenstein helps to elaborate this unease. ${ }^{28}$ If an ontological statement like

(11) The colour red exists

means anything at all, it is either an empirical claim, namely

(11') There are red things

or a statement about language, namely

(11*) The word 'red' has a meaning in our language.

Accordingly, ontological claims are either trivially true (it is obvious, for example, that there are red things), or they do not concern reality but our conceptual framework, just as Carnap had it.

These two interpretations of (11) are indeed natural. Still, Quine would insist that there is a third legitimate interpretation, namely something like

(11\#) Canonical notation features the abstract singular term 'the colour red' (or the ensuing quantifications), and not just general terms like 'red'

For Quine, the question is whether we must include such terms in a language that captures 'all traits of reality worthy of that name'. And he would further maintain that to answer this question is the proper task of ontology. But Carnap and Wittgenstein could reply that $(11 \#)$ is just as linguistic as $\left(11^{*}\right)$; it amounts to nothing other than an answer to an external question, namely: should we adopt a linguistic framework involving abstract colour terms.

Interestingly, Quine concedes that in discussing philosophical problems of existence we tend to shift from talk about objects to talk about words. But he denies that this 'semantic ascent' marks a significant methodological difference (WO §56; see FLPV 15-8, 44-

${ }^{27}$ See Hale, op. cit., ch. 1; B. Stroud, The Significance of Philosophical Scepticism (Oxford: Oxford University Press), 180-97; A. Gallois, 'Does Ontology Rest on a Mistake?', Proceedings of the Aristotelian Society Supplementary Volume LXXII (1998).

${ }^{28}$ Philosophical Investigations, §58.

254 
6, 77-9). Semantic ascent, he explains, occurs in the sciences as well. Furthermore, in so far as an ontological question like that concerning the existence of colours $i$ a pragmatic question about the adoption of a 'linguistic framework', it is no more so than the question of whether our conceptual framework should reckon with the existence of dodos and quarks. In both cases, the alteration of the framework is subject to the same constraints on empirical theory formation. Consequently, the fact that ontologists often talk about words does not show that ultimately their questions concern language rather than reality. As a result, the distinction between external and internal, conceptual and factual, simply collapses.

Here we have reached the crux of the matter. According to Quine's naturalism, ontological reforms of canonical notation are on a par with the adjustment of scientific theories to new empirical evidence.

Each such reform is an adjustment of the scientific scheme, comparable to the introduction or repudiation of some category of elementary physical particle (WO 123).

Ontological statements 'admit of evidence, in the sense that we can have reasons, and essentially scientific reasons' for including numbers or classes in the range of values of our variables, and against including propositions, attributes, or unactualized objects (OR 97). If reference to a type of entities can be avoided through logical paraphrase, this shows that entities of this type do not exist, just as the Michelson-Morley experiment established that the ether does not exist. Conversely, if reference to a type of entities is both part of our best scientific theories and immune to logical paraphrase, this shows that entities of this type do exist, just as the experiments of Cowan and Reines established that neutrinos exist. By this token, the paraphrases of (6) into $\left(6^{\prime}\right)$, and of

(12) Betty possesses wit into

$\left(12^{\prime}\right)$ Betty is witty

are on a par with scientific discoveries concerning the nature of reality.

However, we should be sceptical about the idea that logical paraphrase has such momentous consequences. Paraphrase is a symmetrical relation. ${ }^{29}$ If the paraphrase is adequate, paraphrase $S^{\prime}$ and

${ }^{29}$ W. P. Alston, 'Ontological Commitments', Philosophical Studies 9 (1958); C. Wright, Frege's Conception of Numbers as Objects (Aberdeen: Aberdeen University Press, 1982), ch. I.5. 


\section{Hans-Johann Glock}

original $S$ will say the same. In that case, however, there is no reason to suppose that $S^{\prime}$ will provide us with a more accurate description of reality than $S$. In fact, $\left(6^{\prime}\right)$ implies that red is a colour no less than (6), and $\left(12^{\prime}\right)$ implies that there is a property Betty possesses no less than (12).

Nevertheless, it seems that the existential commitments of

(13) The average Briton drinks 100 litres of beer per annum are indeed brought out by the contextual paraphrase

$\left(13^{\prime}\right)$ If you divide the litres of beer consumed in Britain each year by the number of Britons, you get 100

which makes no reference to the average Briton. In this spirit, Roger Teichmann has argued that there can be an asymmetry between $S$ and $S^{\prime}$, namely if the sentences which parallel $S$ in their logical properties of entailment and compatibility are more often of the form $S^{\prime} \cdot{ }^{30}$ For example

(14) Humility is a virtue

is properly rendered as

$\left(14^{\prime}\right)$ If someone is humble, she is pro tanto virtuous

because its logical powers differ from those of

(15) Fido is a dog.

Unlike (15), (14) entails statements of the form 'If a is F, then a is $\mathrm{G}^{\prime}$ ('If Jane is humble, she is pro tanto virtuous') and does not entail statements like ' $a$ is something that b is not' ('Fido is something that Betty is not').

However, in the one respect that matters to our purposes, namely existential commitment, (14) is like (15). Both entail a statement of the form 'There is at least one F'. It follows that there is a crucial difference between (14) or (6) on the one hand, (13) on the other. While (13) entails neither that there is an average Briton nor that there is someone who drinks 100 litres of beer per annum, (14) entails that humility exists and that there is at least one virtue. Pace Quine, the switch from (12) to $\left(12^{\prime}\right)$ is indeed no more than an 'insignificant quirk of grammar' (WO 241). It involves a change not in existential beliefs, but only in linguistic form. He protests that there is a logical difference between singular and general terms. But that there is a difference between the terms 'wit' and 'is witty' does

${ }^{30}$ R. Teichmann, Abstract Entities (Basingstoke: Macmillan, 1992), $21-4$. 
not entail that there is a difference in existential assumptions between the sentences (12) and (12'). For the difference between the terms is cancelled out by the remainder of the respective sentences.

The moves from (12) to $\left(12^{\prime}\right)$ and from (14) to $\left(14^{\prime}\right)$ do not diminish our commitment to attributes. In fact, $\left(14^{\prime}\right)$ obfuscates rather than illuminates (14). By contrast, in cases like (13), logical paraphrase does clarify our ontological commitments. But even there it does nothing to reduce them. The reason why (13') brings out the commitments of (13) is precisely that the former was never a statement about a putative object-the average Briton-to begin with. Someone who entertains the (in any event curious) desire of marrying the average Briton, will simply have misunderstood the original statement (13).

While it is clear how an explicans can be superior to an explicandum in terms of clarity, it is unclear how it can avoid ontological commitments. Whether someone asserts or is committed to the existence of certain things depends on what she says, not on how she says it. One cannot repeal these admissions simply by modifying one's way of expression. Ergo, the possibility of paraphrasing sentences in a way that avoids explicit reference to entities of a certain type does not reduce our ontological commitments. To use Alston's example, someone who is afraid of policemen would be reassured if she were convinced that there are no policemen, but not by the fact that one can paraphrase 'There is a policeman around the corner' as 'Policemanhood is instantiated around the corner'. The Quinean extensionalist nicely fits Strawson's description 'Committed in thought to what we shun in speech, we should then seem like people seeking euphemisms in order to avoid explicit mention of distasteful realities'. ${ }^{31}$

It is indeed part of the business of science to avoid existential commitments. However, logical paraphrase plays no role in this enterprise. By postulating both phlogiston and oxygen, Priestley's theory creates empirical and theoretical problems that are avoided by Lavoisier's theory, which does away with the former. However, this is not a matter of paraphrasing Priestley's theory, but of developing a new empirical theory that contains no reference to phlogiston, in whatever manner, and yet accounts for the empirical data. Similarly, nuclear physicists may want to avoid commitment to quarks, for example because quarks cannot be observed in isolation. But to that end it does not suffice to reformulate every sentence implying the existence of quarks, for example, into one implying the

${ }^{31}$ Entity and Identity (Oxford: Clarendon, 1997), 58. 


\section{Hans-Johann Glock}

instantiation of quarkhood. Rather, it is a matter of postulating a new set of basic particles that account for the empirical data without having the drawbacks of quarks. In short, it is a matter of scientific work, not of armchair paraphrase à la Quine.

\section{Conclusion}

Quine's naturalistic rehabilitation of ontology is flawed. There is nothing metaphysically daring about referring to or quantifying over abstract objects, or claiming that they exist, provided that we can explain what it is that we are talking about. What has to correspond to our abstract terms is not a system of dubious entities, but an intelligible use. For this reason, we can answer the question 'Do numbers, attributes and propositions exist?' with a resounding 'Yes!', on the basis that this follows from well-established statements, without any bad metaphysical conscience. The existential question has been settled, and the philosophical task turns to clarifying what it is for such objects to exist, to be real, etc. 'Ontological' problems are solved not by positing or depositing entities. Instead, they are solved by clarifying what our various existential claims amount to, and by explaining and contrasting both general ontological notions like 'object', 'thing', 'existent', 'real', and notions from specific forms of discourse, like that of a natural number, of an uninstantiated property, or of an unexpressed proposition.

Quine's logical paraphrase will constitute an important part of such an enterprise. Unlike scientific research, however, it tells us nothing about reality, but at best something about our existential claims and the conceptual framework within which they are made. At this point, Quine might redraft his project of ontological reform. Perhaps our ontological commitments are reduced not by paraphrasing our best actual beliefs, but simply by replacing these beliefs through different ones. Indeed, my suggestion of reducing ontology to conceptual clarification seems to ignore the possibility that our conceptual scheme-including the conceptual scheme of science-may be based on false assumptions about what there is, assumptions which ontology should correct rather than clarify.

But this move is not available to Quine. His naturalism leaves him without a platform from which to criticize the claims of successful scientific disciplines. More importantly still, the revisionist move is also inherently dubious. To settle the question of whether nonphilosophical existence statements are true, all one can do is to establish whether the conditions obtain that these statements claim 
to obtain. And while philosophers can on occasion help in clarifying what these conditions are, they have no special brief for establishing whether they obtain. At best they can show that some existential statements could not possibly be true, because they involve inconsistent concepts like that of a round square. To suppose otherwise is to go back to the pre-Kantian and un-Quinean idea of philosophy as a super-science capable of overruling the special sciences.

There are important similarities and connections between scientific and ontological investigations in my deflationary sense. To clarify scientific concepts, one needs to know science; but this is not the same as to $d o$ science. Conversely, theoretical science also deals with concepts. But it does so by devising new concepts for the sake of explaining empirical findings, not by spelling out the implications of established concepts and beliefs. Linné and Gell-Man advanced biology and nuclear physics, respectively, through novel classification schemes; and devising such schemes is also a pastime of analytic ontologists. However, scientific classifications and conceptual innovations are directly driven by empirical data. By contrast, in typical ontological conflicts, the facts are clear, and the dispute is one of how to describe them. For example, philosophers who disagree on whether mental causation exists will usually agree that people often do things because they want to.

Perhaps there are existential investigations that are both distinctly philosophical and responsible to empirical facts, like 'the introduction or repudiation of some category of elementary physical particle'. But Quine's programme of ontological reform is curiously immune to experience. His hostility to intensions is based not on empirical evidence, but on a priori scruples concerning the conceptual framework within which that evidence is weighed. Quine comes close to conceding even this point (WO 275-6; OR 98-9). Nonetheless, he insists that his reforms are indirectly connected with experience through their place within a web of beliefs. Even if accurate, however, this holistic picture provides no argument for assimilating the extensionalist purge of language to the scientific quest of limning the ultimate constituents of reality. That two things are somehow connected does not show that there are no qualitative differences between them.

There may well be promising rehabilitations of ontology not considered here, in particular if the enterprise is linked to rather than contrasted with conceptual analysis. ${ }^{32}$ So far, however, there is no compelling reason to believe that ontology exists. The projects that

${ }^{32}$ Notably F. Jackson, From Metaphysics to Ethics: A Defence of Conceptual Analysis (Oxford: Clarendon, 1998). 


\section{Hans-Johann Glock}

have shaped analytic ontology to date do not provide us with genuinely philosophical discoveries about the world, whether with or without the aid of the special sciences. ${ }^{33}$

The University of Reading

${ }^{33}$ I am grateful to the Alexander von Humboldt Foundation for a research grant. For comments and advice I should like to thank David Bakhurst, Ansgar Beckermann, Peter Hacker, Anthony O’Hear, John Hyman, Wolfgang Künne, Christian Nimtz, Jay Rosenberg and Eike von Savigny, as well as audiences at Bielefeld, Konstanz, Vercelli and Kingston (Ontario).

260

CAMBridge JDURNALS 